\title{
A survivability model for ejection of green compacts in powder metallurgy technology
}

\author{
Payman Ahi $^{\mathbf{a}^{*}}$, Kouroush Jenab ${ }^{\mathrm{a}}$, Ahmad Ghasempoor ${ }^{\mathrm{a}}$ and Mark Rajai ${ }^{\mathrm{b}}$
}

${ }^{a}$ Department of Mechanical and Industrial Engineering, Ryerson University, Toronto, Canada

${ }^{b}$ Department of Manufacturing Systems Engineering and Management, California State University-Northridge, Northridge, USA

\begin{tabular}{|c|c|}
\hline A R T I C L E I N F O & A B S T R A C T \\
\hline $\begin{array}{l}\text { Article history: } \\
\text { Received 1 August } 2011 \\
\text { Available online } \\
10 \text { August } 2011 \\
\text { Keywords: } \\
\text { Survivability model } \\
\text { Green compact } \\
\text { Density } \\
\text { Tensile failure stress } \\
\text { Ejection } \\
\text { Failure model }\end{array}$ & $\begin{array}{l}\text { Reliability and quality assurance have become major considerations in the design and } \\
\text { manufacture of today's parts and products. Survivability of green compact using } \\
\text { powder metallurgy technology is considered as one of the major quality attributes in } \\
\text { manufacturing systems today. During powder metallurgy (PM) production, the } \\
\text { compaction conditions and behavior of the metal powder dictate the stress and density } \\
\text { distribution in the green compact prior to sintering. These parameters greatly } \\
\text { influence the mechanical properties and overall strength of the final component. In } \\
\text { order to improve these properties, higher compaction pressures are usually employed, } \\
\text { which make unloading and ejection of green compacts more challenging, especially } \\
\text { for the powder-compacted parts with relatively complicated shapes. This study looked } \\
\text { at a mathematical survivability model concerning green compact characteristics in PM } \\
\text { technology and the stress-strength failure model in reliability engineering. This model } \\
\text { depicts the relationship between mechanical loads (stress) during ejection, } \\
\text { experimentally determined green strength and survivability of green compact. The } \\
\text { resulting survivability is the probability that a green compact survives during and after } \\
\text { ejection. This survivability model can be used as an efficient tool for selecting the } \\
\text { appropriate parameters for the process planning stage in PM technology. A case } \\
\text { study is presented here in order to demonstrate the application of the proposed } \\
\text { survivability model. }\end{array}$ \\
\hline
\end{tabular}

C) 2012 Growing Science Ltd. All rights reserved

\section{Introduction}

The economic environment is becoming increasingly harsh. Consumer demands on the emerging world economy are for improving the performance of products and manufacturing processes, while at the same time reducing their costs. The requirements for minimizing the probability of failures, whether those failures simply increase costs or harm the users in any way, are placing increased emphasis on product reliability. Powder metallurgy is one manufacturing process that is being used particularly for the manufacture of relatively complex parts. The availability of a wide range of powder compositions, the capability of producing parts to exacting dimensions, and the economics of the overall operation have made this process attractive for many applications in diverse industries such as aerospace, biomedical engineering, automotive and machinery. Powder metallurgy has the

* Corresponding author Tel.: (416) 979-5000 Ext. 2228

E-mail: payman.ahi@ryerson.ca (P. Ahi) 
ability to make near-net-shaped parts at a high material utilization ratio and the flexibility to tailor material properties to suit the application. The manufacturing process of a powder-compacted part may roughly be divided into two steps. The first step is the compaction of the metal powder (cold die compaction), where plastic deformation of powder particles is the major deformation process; this is the focus of the present study. The second step is the heat treatment or sintering of a compacted part in order to bond the powder particles together.

Die compaction is widely used to characterize the mechanical behavior of powders. During the compaction process, the powder undergoes a transformation from a loose state to a dense, compacted state. The purpose of the compaction process is to obtain the required shape, density, and interparticle metallic contact to make the part sufficiently strong. During PM production, the compaction conditions and the behavior of the metal powder dictate the stress and density distribution in a green compact prior to sintering. These parameters have a great influence on the overall strength of the final part. Therefore, accurate control of the forces applied during the compaction process is critical for ensuring that the required density, strength, and dimensional specifications are attained (Smith et al., 1998).

The formation of a powder compact can roughly be divided into the following identifiable stages: filling, compaction, unloading and ejection. One of the most important properties of the powder is its compressibility, which determines the density of the part at a given compaction pressure (Senthilvelan et al., 2003a). An increase in density, which has positive effects on toughness and reliability, increases the volume of the material that undergoes plastic deformation before fracture (Straffelini and Molinari, 1996). Powder metallurgy manufacturers usually rely on part density as a means of controlling part performance. Therefore, they use higher compaction pressures to obtain higher densities and better properties. On the other hand, compaction induces a complex state of stress in the powder (Briscoe and Rough, 1998) and ejection stresses usually increase with compacting pressure (Lefebvre and Mongeon, 2003).

During the ejection cycle, radial stress relaxation occurs as the green compact exits from the die. This can generate a stress state that significantly affects the green compact's characteristics such as surface finish, formation of cracks and lamination. As a result, the unloading and ejection stages can impact a green compact's integrity. For iron powders compacted to very high pressures (typically $800 \mathrm{MPa}$ ), press and die deflections become important issues. Under these circumstances for multilevel components, die elastic recovery can be differential during the unloading stage (Korachkin et al., 2008). This imposes loads on the green powder compact that cannot be sustained and leads to tensile failure or crack formation. Die pressing of the metal powder often results in a powder compact with a non-uniform density distribution, mainly because of friction between the die wall and the powder (Redanz, 1999; Sopchak and Misiolek, 2000). Friction is an important factor for all stages that can cause density variation throughout the compacted part.

Minimizing the probability of failures, which may increase costs or hazard risks, requires more emphasis on the reliability analysis. Therefore, a mathematical survivability model is proposed in this study that considers the important factors involved in the cold compaction process as well as the basic principles of reliability modeling. A relationship between strength, stress, and survivability of green compact was investigated to determine the probability that a green compact could survive during and after ejection. This survivability model can be used as a tool for selecting the appropriate parameters for the process planning stage in PM technology.

\section{Notations}


$l \quad$ Random variable representing applied load (stress)

$n \quad$ Number of samples tested

$p \quad$ Random variable representing compaction pressure

$\hat{p} \quad$ Maximum value for $p$

Random variable representing tensile failure stress

$\hat{r} \quad$ Maximum value for $r$

$S_{r} \quad$ Survivability of green compact

$\sigma_{p}$

Standard deviation of the variable $p$

$\sigma_{r}$

Standard deviation of the variable $r$

Standard deviation of the variable $g$

$\sigma_{g}$

Mean value of the variable $p$

$\mu_{p}$

Mean value of the variable $r$

$\mu_{r}$

Mean value of the variable $g$

$\mu_{g}$

Correlation coefficient between variables $p$ and $g$

$\rho_{p g}$

Covariance between variables $p$ and $g$

\section{Survivability model}

The primary goal of a survivability analysis is to act as an aid in the process or product design stage. In powder compaction, and specifically for unloading and ejection stages, it is necessary to estimate the green compact's survivability, which is defined as the probability that the strength of the powdercompacted part (green strength) is greater than the stresses (loads) applied to the part during the unloading and ejection stages. Green compact's strength is a term used in powder metallurgy to characterize the mechanical strength of PM parts in the compaction stage. It is the result of the bonding force in particle-to-particle metallic contact during the compaction process and subsequent cold welding of the particles (Senthilvelan et al., 2003b).

In order to understand the survivability of green compact, it is necessary to know its failure behavior(s) and also the factors that cause these failures (DeWolf, 2003). The survivability model can be constructed for all failure modes when they are well understood. Such a model would then allow lifetime predictions that would also make it possible to take into account the influence of environmental parameters on any particular failure mode. The model in turn can be used as a design tool to improve the survivability of products. As shown in Fig. 1, failure is caused by stresses (i.e., tensile stress) applied during the unloading and ejection stages. The green compact of a PM part has an inherent strength to withstand such stresses, which may be reduced by specific internal or external conditions. A failure occurs when the stresses exceed the green compact's strength. Undesirable conditions may occur naturally or artificially, internally or externally, and will increase stresses applied to the green compact and/or reduce the strength of the green compact in order to tolerate the stresses. The structure presented in Fig. 1 is consistent with several, simple failure models presented by Dasgupta and Pecht (1991). One of the common failure models for mechanical components is the stress-strength model presented by Lewis and Chen (1994). Based on this failure model (also known as the load-capacity model), a part fails if and only if the applied load exceeds the part's strength. The load represents an aggregate of the challenge and external conditions (i.e., tensile stress during the unloading and ejection stages). This failure model may depend on environmental conditions or the occurrence of critical events, rather than the simple passage of time or cycles. Strength is often treated as a random variable representing effects of all conditions influencing the part's strength or lack of precise knowledge about the part's strength. In this failure model, challenges are caused by failure-inducing agents. Mechanical loads (stresses) are one of the most important failure-inducing agents. A comprehensive consideration of survivability requires analysis of this failure-inducing agent. Mechanical loads may be analyzed deterministically (e.g., by identifying the sources of stress), or probabilistically (e.g., by treating stresses as a random variable). In either case, it is necessary to 
understand why and how such loads (stresses) lead to failure. This would require studying the mechanics of the failure in general and the failure mechanisms in particular. In order to mathematically model the survivability of green compact, a detailed understanding of the related failure model is necessary.

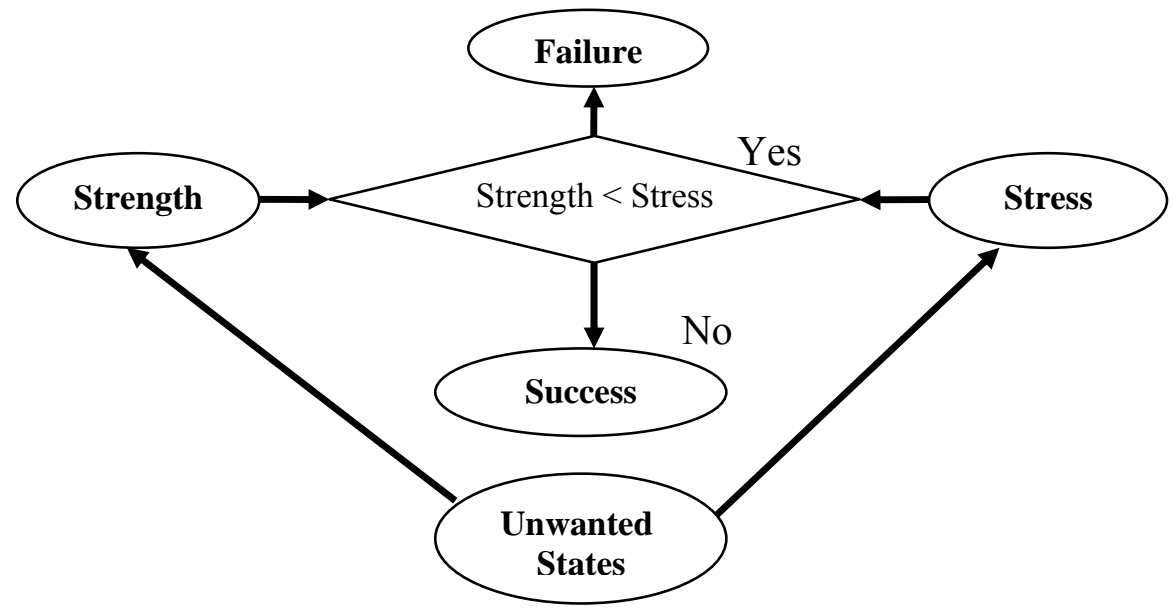

Fig. 1. Framework of failure modeling

Considering the stress-strength failure model, a green compact fails if the applied stresses exceed the green compact's strength. For the powder-compacted parts under consideration, the first step is to determine the factors that affect the stress and strength calculations. Also, the probability distributions of such influencing factors are required. This information can be obtained from experimental data for a given set of process parameters. Considering the selected failure model, these distributions are then used to compute the survivability of the green compact.

In this study, the compaction pressure and density were considered as major variables affecting the strength of the green compact; all other parameters were assumed to be constant. Also, the tensile stress was assumed to be the only loading factor applied to the green compact during the unloading and ejection stages. Therefore, if the probability density function (PDF) for the compaction pressure, $P$, is denoted as $f(p)$, then the corresponding cumulative density function (CDF) for the compaction pressure can be defined as:

$F(p)=\int_{0}^{\hat{p}} f(p) d_{p}$

Similarly, if the PDF for the green compact's density, $G$, is denoted as $f(g)$, then the corresponding $\mathrm{CDF}$ for the green density can also be defined as:

$F(g)=\int_{0}^{\hat{g}} f(g) d_{g}$

Also, if the PDF for the load (stress), $L$, is denoted as $f(l)$, then the corresponding CDF for the load can be defined as:

$F(l)=\int_{0}^{l} f(l) d_{l}$

Considering Eq. (1) and Eq. (2) for the factors affecting the strength of the green compact, the corresponding CDF for the strength of the item under consideration can be defined as: 
$F(s)=\int_{0}^{\hat{g}} \int_{0}^{\hat{p}} f(p, g) d_{p} d_{g}$

where $f(p, g)$ is a joint PDF constructed from random variables of compaction pressure and the green compact's density, which jointly define a variable " $S$ " representing strength of the green compact. By considering the stress-strength failure model concept and applying Eq. (3) and Eq. (4), the survivability of green compact can be defined as:

$S r=\int_{0}^{\hat{g}} \int_{0}^{\hat{p}} f(p, g)\left[\int_{0}^{S} f(l) d_{l}\right] d_{p} d_{g}$

As defined in Eq. (5), survivability of the green compact is the probability that the powder-compacted part will survive the application of loads (stresses) under certain conditions. In the case of highpressure compaction, these critical loads are present during the unloading and ejection cycles. Die elastic recovery during the unloading stage will impose loads on the green compact leading to tensile failure if it cannot be sustained. During the ejection cycle, the striping and sliding pressures are required to get the compact moving inside the die. These pressures are required to overcome the static and dynamic friction between the powder and the die walls and will impose stresses on the green compact during the ejection cycle. These stresses could result in the formation of cracks, and potentially lead to tensile failure in the ejected powder-compacted part.

Since experimental measurement of the imposed stresses during the unloading and ejection cycles is difficult, three-point bending-test results were used in this study to model the green compact's behavior during ejection. Three-point bending is a common test for assessing the tensile strength of powder-compacted parts. The relationship between applied load and tensile failure stress is given by Poquillon et al. (2002):

$\sigma=\frac{3 F d}{2 b h^{2}}$

where:
$\sigma=$ Tensile Failure Stress
$F=$ Applied Force (Load)
$d=$ Distance between two supports
$b=$ Width of the specimen
$h=$ Height of the specimen

Therefore, if the PDF for the generated tensile failure stress, $\sigma$, is denoted as $f(r)$, then the corresponding $\mathrm{CDF}$ for the tensile failure stress is expressed by:

$F(r)=\int_{0}^{\hat{r}} f(r) d_{r}$

Based on ISO7438, parameters $d, b$ and $h$ in Eq. (6) should be kept unchanged during three-point bending tests, therefore, by replacing the applied load (stress), $L$, with the tensile failure stress, $\sigma$, in Eq. (5), survivability of the green compact could be interpreted as the probability that the green compact's strength exceeds the tensile failure stress resulting from application of a single load. Therefore: 
$S r=\int_{0}^{\hat{g}} \int_{0}^{\hat{p}} f(p, g)\left[\int_{0}^{\hat{r}} f(r) d_{r}\right] d_{p} d_{g}$

Considering the bivariate normal distribution for $f(p, g)$, the correlation between parameters involved in formation of the green compact's strength was assumed to be linear. Also, all the parameters in the proposed survivability model $(p, g$ and $r$ ) were assumed to be normally distributed. Therefore, $f(r)$ and $f(p, g)$ are defined as follows:

$f(r)=\frac{1}{\sigma_{r} \sqrt{2 \pi}} e^{-\frac{\left(r-\mu_{r}\right)^{2}}{2 \sigma_{r}^{2}}}$

and

$$
f(p, g)=\frac{1}{2 \pi \sigma_{p} \sigma_{g} \sqrt{1-\rho_{p g}^{2}}} e^{-\frac{z_{p g}}{2\left(1-\rho_{p g^{2}}\right)}}
$$

where:

$z_{p g}=\frac{\left(p-\mu_{p}\right)^{2}}{\sigma_{p}^{2}}-\frac{2 \rho_{p g}\left(p-\mu_{p}\right)\left(g-\mu_{g}\right)}{\sigma_{p} \sigma_{g}}+\frac{\left(g-\mu_{g}\right)^{2}}{\sigma_{g}^{2}}$

$\rho_{p g}=\frac{v_{p g}}{\sigma_{p} \sigma_{g}}$

$v_{p g}=\frac{1}{n-1} \sum_{i=1}^{n}\left(p_{i}-\mu_{p}\right)\left(g_{i}-\mu_{g}\right)$

Considering Eq. (8), Eq. (9) and Eq. (10), survivability of the green compact can be expressed by:

$$
S_{r}=\int_{0}^{\hat{g}} \int_{0}^{\hat{p}} \frac{1}{2 \pi \sigma_{p} \sigma_{g} \sqrt{1-\rho_{p g}^{2}}} e^{-\frac{z_{p g}}{2\left(1-\rho_{p g^{2}}\right)}}\left[\int_{0}^{\hat{r}} \frac{1}{\sigma_{r} \sqrt{2 \pi}} e^{-\frac{\left(r-\mu_{r}\right)^{2}}{2 \sigma_{r}^{2}}} d_{r}\right] d_{p} d_{g}
$$

By obtaining the required data for parameters involved in the proposed survivability model $(p, g$ and $r$ ), which are relatively easy to obtain experimentally, the value of survivability for any green compact under consideration can be calculated.

\section{Illustrative case study}

In order to illustrate the application of the proposed survivability model, experimental data for the green compacts made by die pressing of ferrous powders was used. Five nominal set-points of 100, 150, 200, 265 and $300 \mathrm{MPa}$ were considered for the compaction pressures. Five samples of green compacts were made at each compaction set point. The relative density for each compacted sample was calculated and followed by a three-point bending test. The geometry of samples was kept the same throughout the experiment. Using the experimental data and applying Eq. (14), survivability of 
the green compact at each of the compaction pressures was determined. The results of this calculation are shown in Fig. 2.

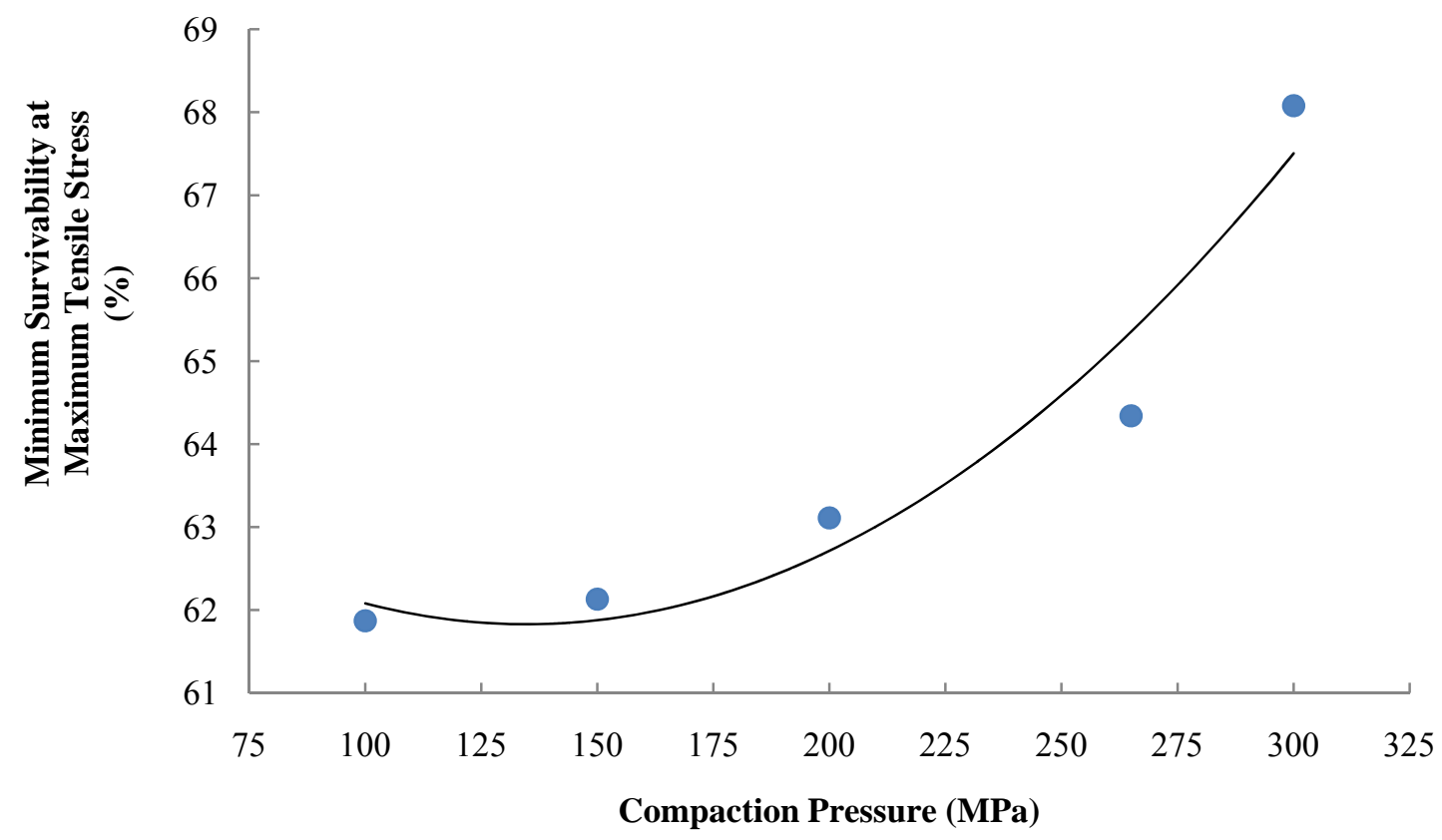

Fig. 2. Relation between compaction pressure and minimum survivability at maximum tensile stress during ejection

These results represent the minimum survivability of green compact when the ejection stress (load) is at its maximum level. The ejection stresses applied to the green compact are typically much lower (Redanz, 2001), resulting in substantially higher survivability. To explore the situations when the stress applied to the powder-compacted part during ejection is less than maximum tensile strength, the proposed model was used to calculate the survivability of green compact when the ejection stresses are 5, 10, 25, 50, 75, 87.5 and $100 \%$ of the average tensile failure stress at each compaction pressure. For every considered level of ejection stress, the same standard deviation (extracted from the experimental data for tensile failure stress) was used to generate 10 sets of data. Applying the proposed model and using this data, the survivability was calculated for each set of data separately. The mean of the calculated values was considered as the survivability of green compact for that particular ejection stress at each compaction pressure. The results are shown in Table 1.

Analysis of the results from Table 1 verifies that for ferrous powder, under the compaction pressure of $150 \mathrm{Mpa}$, for example, an increase in the ejection stress from 1.12 to $22.45 \mathrm{MPa}$, results in a reduction of survivability from 74.05 to $68.71 \%$. Similarly, at the compaction pressure of $300 \mathrm{MPa}$ (the highest compaction pressure used in this study), if the ejection stress increases from 2.20 to $43.86 \mathrm{MPa}$, the survivability of green compact will be reduced from 78.06 to $71.86 \%$. To create a more comprehensive model for the survivability of green compact during the ejection stage, the experimental data was used to fit a continuous curve representing the relationship between survivability and ejection stress. Since survivability against ejection will be $100 \%$ when the tensile stresses are absent, the following function form was found to be the most suitable:

$\hat{S}_{r}=\left(100-S_{\min }\right) e^{-k \sigma_{\max }}+S_{\min }$

where:

$$
\hat{S}_{r}=\text { Survivability curve }
$$


Table 1

$S_{\min }=$ Minimum survivability at maximum ejection stress

$\sigma_{\max }=$ Maximum ejection stress

$k=$ Model parameter

Ejection stresses and survivability of green compact at each compaction pressure

\begin{tabular}{|c|c|c|}
\hline Compaction Pressure (MPa) & Ejection Stress (MPa) & Survivability $(\%)$ \\
\hline \multirow{7}{*}{100} & 0.76 & 74.14 \\
\hline & 1.52 & 74.01 \\
\hline & 3.80 & 73.73 \\
\hline & 7.60 & 73.04 \\
\hline & 11.38 & 72.33 \\
\hline & 13.27 & 71.52 \\
\hline & 15.17 & 70.71 \\
\hline \multirow{7}{*}{150} & 1.12 & 74.05 \\
\hline & 2.25 & 73.04 \\
\hline & 5.61 & 72.25 \\
\hline & 11.22 & 71.31 \\
\hline & 16.84 & 70.40 \\
\hline & 19.64 & 69.65 \\
\hline & 22.45 & 68.71 \\
\hline \multirow{7}{*}{200} & 1.50 & 73.14 \\
\hline & 3.00 & 72.81 \\
\hline & 7.52 & 71.33 \\
\hline & 15.05 & 70.66 \\
\hline & 22.56 & 69.84 \\
\hline & 26.32 & 68.37 \\
\hline & 30.07 & 67.77 \\
\hline \multirow{7}{*}{265} & 1.87 & 74.10 \\
\hline & 3.73 & 74.02 \\
\hline & 9.33 & 73.34 \\
\hline & 18.65 & 72.49 \\
\hline & 27.98 & 71.92 \\
\hline & 32.64 & 70.58 \\
\hline & 37.31 & 69.35 \\
\hline \multirow{7}{*}{300} & 2.20 & 78.06 \\
\hline & 4.39 & 77.36 \\
\hline & 10.98 & 75.32 \\
\hline & 21.93 & 74.32 \\
\hline & 32.90 & 73.70 \\
\hline & 38.39 & 72.86 \\
\hline & 43.86 & 71.86 \\
\hline
\end{tabular}

Using the data in Table 1, the required parameters for the survivability curve were calculated, as shown in Table 2.

Table 2

Parameters of the survivability function form

\begin{tabular}{llll}
\hline Compaction Pressure $(\mathrm{MPa})$ & $\sigma_{\max }(\mathrm{MPa})$ & $K$ & $S_{\min }(\%)$ \\
\hline 100 & $\leq 15.17$ & 3.5512 & 72.5060 \\
150 & $\leq 22.45$ & 1.2720 & 70.7409 \\
200 & $\leq 30.07$ & 1.3813 & 69.9567 \\
265 & $\leq 37.31$ & 1.8285 & 71.8518 \\
300 & $\leq 43.86$ & 0.7415 & 73.9243 \\
\hline
\end{tabular}

By applying the Eq. (15), the survivability of green compact against different ejection stresses at compaction pressures of 150 and $300 \mathrm{MPa}$ are shown in Fig. 3 and Fig. 4. 


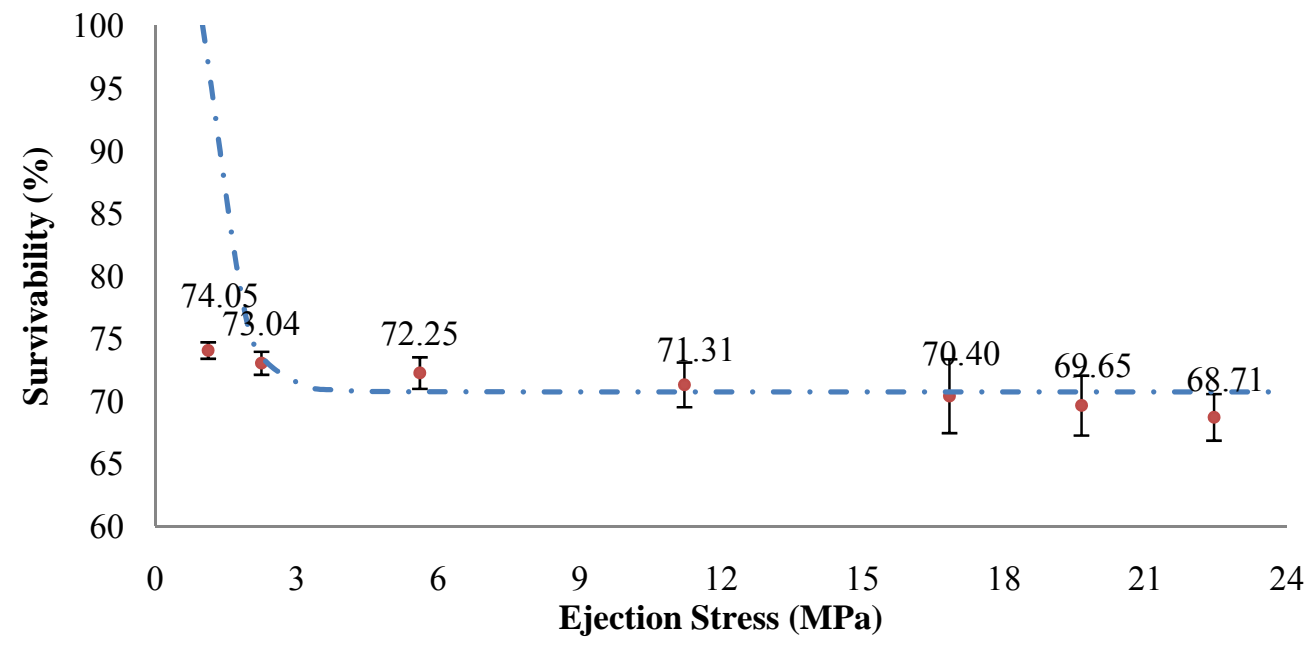

Fig. 3. Survivability behavior against ejection stress at $150 \mathrm{MPa}$ compaction pressure $(\alpha=5 \%)$

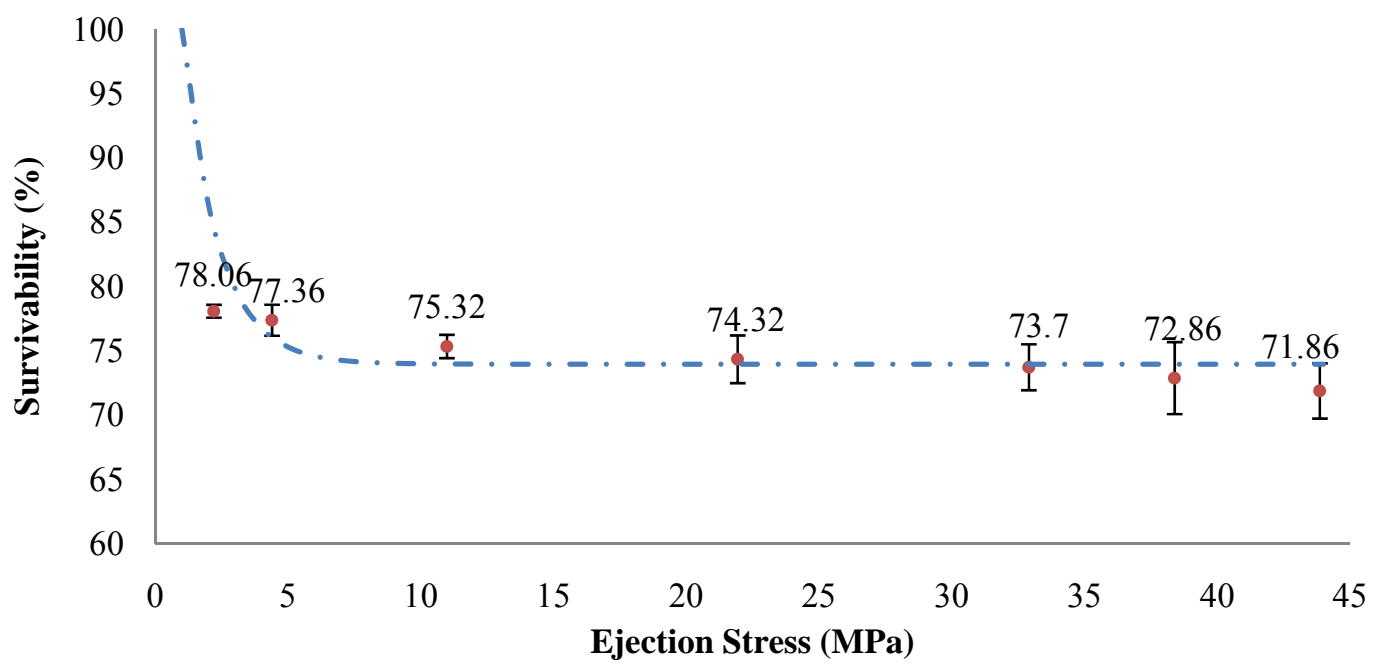

Fig. 4. Survivability behavior against ejection stress at 300MPa compaction pressure $(\alpha=5 \%)$

By using the information in Fig. 2, one can easily evaluate the survivability of a green compact with a compaction pressure in the range of 100 to $300 \mathrm{MPa}$. If the ejection stresses present during the ejection stage are known, Eq. (15) can be applied to the data from Table 2 to evaluate the survivability of the green compact. This makes it possible to evaluate the effect of various process parameters on the process yield, and make the appropriate decisions accordingly. High yield of green compacts prior to sintering is of prime importance, and being able to calculate the survivability against ejection stresses will be beneficial. Therefore, by controlling the compaction process, manufacturers can ensure that the desirable density, required strength and the desired yield will be attained. The proposed survivability model can be used as an effective tool for proper selection of design parameters.

\section{Conclusion}

It is necessary to take into account the manufacturing capabilities and limitations as well as the material data in order to reduce design iteration and to minimize the trial and error required at the manufacturing stage. The die compaction process results in a powder-compacted part with an inhomogeneous density distribution. The higher the green density (density after compaction), the higher will be the strength of the powder-compacted part and, hence, the greater will be the green compact's resistance to external forces. Considering the green compact's integrity, both the unloading and ejection stages can be crucial. Tool deflection during compaction, elastic recovery in the 
unloading stage along with the ejection stresses are important considerations since they impose loads on the green compact, which may not be sustainable and ultimately lead to tensile failure.

In this study, a mathematical survivability model based on the stress-strength failure model was developed. In order to illustrate the application of the proposed survivability model, results from three-point bending tests, representing the state of maximum possible stress during and after the ejection stage, were employed. It was shown that the survivability of green compact was improved by increasing the compaction pressures from 100 to $300 \mathrm{MPa}$ (the selected range for the compaction pressures). It was also shown that for each compaction pressure, a decrease in tensile failure stress will increase survivability of the green compact during ejection. Considering the fact that ejection stresses applied to the green compact are typically lower than its maximum tensile strength, the proposed survivability model was also used to calculate the survivability of green compact when the ejection stresses vary between 5 and $100 \%$ of the average tensile failure stress at each compaction pressure. The statistical analysis of these calculations confirmed that increasing values of stress during the ejection cycle would cause the survivability of green compact to decrease exponentially. For the powder-compacted parts with more complicated geometry, a finite element model was employed to estimate the stresses applied to the green compact during the ejection cycle. The results will be used to demonstrate the application of the proposed survivability model.

It is necessary to consider that design and manufacturing must be closely interrelated and should never be viewed as separate disciplines or activities. Careful design, using the best established design practices, computational tools, and manufacturing techniques, are the optimum approach for achieving high-quality products and realizing cost savings.

\section{References}

Briscoe, B.J. and Rough, S.L. (1998). The effects of wall friction in powder compaction. Colloids and Surfaces, A: Physicochemical and Engineering Aspects, 137(1-3), 103-116.

Dasgupta, A. and Pecht, M. (1991). Materials Failure Mechanisms and Damage Models. IEEE Transactions on Reliability, 40 (5), 531-536.

DeWolf, I. (2003). MEMS reliability. Microelectronics Reliability, 43 (7), 1047-1048.

ISO7438. (1985). Metallic Materials - Bend Test.

Korachkin, D., Gethin, D.T., Lewis, R.W., Tweed, J.H., \& Guyoncourt, D. M.M. (2008). Measurement of Young's modulus and tensile failure properties of green powder compacts. Powder Metallurgy, 51 (2), 150159.

Lefebvre, L.P. and Mongeon, P.E. (2003). Effect of tool coatings on ejection characteristics of iron powder compacts. Powder Metallurgy, 46 (1), 43-48.

Lewis, E.E. and Chen, H.C. (1994). Load-Capacity Interference and the Bathtub Curve. IEEE Transactions on Reliability, 43 (3), 470-475.

Poquillon, D., Baco-Carles, V., Tailhades, Ph., \& Andrieu, E. (2002). Cold compaction of iron powdersrelations between powder morphology and mechanical properties Part II: Bending tests, results and analysis. Powder Technology, 126 (1), 75-84.

Redanz, P. (1998). Numerical modeling of cold compaction of metal powder. International Journal of Mechanical Science, 40 (11), 1175-1189.

Redanz, P. (2001). A study of stresses in powder compacted components during and after ejection. International Journal of Solids and Structures, 38 (5), 759-775.

Senthilvelan, T., Raghukandan, K., \& Venkatraman, A. (2003a). Testing and Quality Standards for Powder Metallurgy Products. Materials and Manufacturing Processes, 18 (1), 105-112.

Senthilvelan, T., Raghukandan, K., \& Venkatraman, A. (2003b). Tooling Design and Compaction Analysis on P/M Copper Bushes. Materials and Manufacturing Processes, 18 (1), 113-122.

Smith, L.N., Midha, R.P., \& Graham, A.D. (1998). Simulation of metal powder compaction, for the development of a knowledge based powder metallurgy process advisor. Journal of Materials Processing Technology, 79 (1-3), 94-100.

Sopchak, N. D. and Misiolek, W. Z. (2000). Density Gradients in Multilayer Compacted Iron Powder Parts. Materials and Manufacturing Processes, 15 (1), 65-79.

Straffelini, G. and Molinari, A. (1996). Microstructure and mechanical reliability of powder metallurgy (P/M) Ferrous Alloys. Journal of Materials Engineering and Performance, 5 (1), 27-33. 